\title{
Computerized Stroop Test to Assess Selective Attention in Children with Attention Deficit Hyperactivity Disorder
}

\author{
Ellen Carolina dos Santos Assef ${ }^{1}$, Alessandra Gotuzo Seabra Capovilla ${ }^{1}$, \\ and Fernando Cesar Capovilla ${ }^{2}$ \\ ${ }^{1}$ Universidade São Francisco, Brazil \\ ${ }^{2}$ Universidade de São Paulo, Brazil
}

\begin{abstract}
Research shows abnormal function of the pre-frontal cortex in Attention Deficit Hyperactivity Disorder (ADHD). This cortex is involved in the control of executive functions related to planning and execution of goal-oriented strategies, working memory, inhibitions, cognitive flexibility, and selective attention. Selective attention involves focus on the target stimulus, ignoring competing distractions. The Stroop Test (Stroop, 1935) is usually used to evaluate selective attention. This study investigated whether children with ADHD could exhibit modified performance in the Stroop Test. Using a computerized version of this test (Capovilla, Montiel, Macedo, \& Charin, 2005), the study compared the reaction times (RTs) of 62 Brazilian children, between 8 and 12 years of age, 31 of whom were diagnosed with ADHD and sent to psychiatric clinics, and 31 without ADHD studying in regular schools. All children with ADHD satisfied the criteria of the DSM-IV-TR and were evaluated with the Conners Abbreviated Questionnaire (Goyette, Conners, \& Ulrich, 1978), completed by parents and teachers. The results revealed that children with ADHD exhibit greater interference in RT than children without ADHD. This corroborated the hypothesis that children with ADHD exhibit a deficit in selective attention, consisting in augmented RTs, as measured by the Computerized Stroop Test.
\end{abstract}

Keywords: Stroop Test, ADHD, neuropsychology, selective attention, executive functions

\begin{abstract}
La investigación ha mostrado la función anormal del córtex prefrontal en el trastorno de déficit de atención con hiperactividad (TDAH). Este córtex está implicado en el control de las funciones ejecutivas relacionadas con la planificación y ejecución de estrategias orientadas a objetivos, la memoria de trabajo, las inhibiciones, la flexibilidad cognitiva y la atención selectiva. La atención selectiva implica centrarse en el estímulo diana, ignorando las distracciones que compiten para la atención. Normalmente se emplea la prueba Stroop (Stroop, 1935) para evaluar la atención selectiva. En este estudio se investigó si le ejecución en la prueba Stroop de niños con TDAH podría sufrir modificaciones. Empleando una versión informatizada de esta prueba (Capovilla, Montiel, Macedo y Charin, 2005), el estudio comparó los tiempos de reacción (TR) de 62 niños brasileños, con edades entre los 8 y los 12 años, de los cuales 31 fueron diagnosticados de TDAH y estaban en clínicas psiquiátricas, y 31 sin TDAH que estudiaban en colegios normales. Todos los niños con TDAH cumplían los criterios del DSM-IV-TR y fueron evaluados con el Cuestionario Abreviado de Conners (Goyette, Conners y Ulrich, 1978), cumplimentado por padres y profesores. Los resultados revelaron que los niños con TDAH mostraron más interferencia en TR que los niños sin TDAH. Esto corroboró la hipótesis de que los niños con TDAH exhiben un déficit en la atención selectiva, que consiste en TR aumentados, tal y como se miden con la Prueba Stroop Informatizada.

Palabras clave: Prueba Stroop, TDAH, neuropsicología, atención selectiva, funciones ejecutivas
\end{abstract}

Correspondence concerning this article should be sent to Alessandra Gotuzo Seabra Capovilla, Post-Graduate Program Strict Sense in Psychology of the University of Sao Francisco, Av. Alexandre Rodrigues Barbosa, 45 - Centro - Itatiba - SP, CEP $13251-900$ (Brazil). Phone: 5511 4534-8040. Fax: 5511 4524-1933.

E-mail: acapovil@usp.br, alessandra.capovilla@saofrancisco.edu.br 
The diagnosis of attention deficit hyperactivity disorder is fundamentally clinical, based on criteria from classificatory systems such as the International Classification of Diseases (ICD-10; World Health Organization, 1992) and the Diagnostic and Statistical Manuel of Mental Disorders, $4^{\text {th }}$ edition, text revision (American Psychiatric Association, 2000). The predominant behavioral character of the symptomatology of the disorder, in the majority of cases identified in infantile populations, renders discrimination between the illness and maladjusted behavior from environmental factors difficult. Allied to such behavioral alterations, there are cognitive alterations that must be studied and understood better.

Since the first definitions of the disorder, it has been speculated to be based on the neurons involved. Currently, the consensus that there is a cerebral dysfunction has driven research to incorporate other areas to understand the phenomenon. Neuropsychology has been one of the areas emphasized in the investigation of the relationship between behavior, cognition, and the central nervous system (Gazzaniga, Ivry, \& Mangun, 2002; Gil, 1999; Luria, 1973). The combination of sophisticated techniques of neuroimaging and neuropsychological evaluations has corroborated the hypothesis of the presence of a cerebral malfunction in children with ADHD, and improved understanding of the cognitive mechanisms involved.

Phenomena characteristic of ADHD, such as difficulty in maintaining attention, control of behavior and distracting thoughts, and control of motor function (Barkley, 1997; Houghton et al., 1999; Mattos, 2002), have been associated with frontal encephalic alterations, but especially pre-frontal ones. These cortical regions are principally responsible for coordination, integration, maintenance, and monitoring of further cognitive functions related to other cerebral areas. Called "executive functions," this group of frontal abilities has been understood basically as consisting of the ability to form action strategies to achieve goals and objectives (Damásio, 1995; Gazzaniga, et al., 2002; Goldberg, 2002; Kerns \& Berembaum, 2003; Lezak, 1995). Such functions are not united, but involve components such as the ability to select information, planning, attention monitoring, organization of memorization strategies, discrimination of memories, inhibition of interference during a memory, and cognitive flexibility (Gazzaniga et al., 2002; Lezak, 1995).

In fact, according to various authors, malfunctions in the pre-frontal cortex and their connections to the subcortical network may be responsible for behaviors typical of ADHD, such as deficits in behavioral inhibitions, working memory, planning, attention, self-control, and directing action toward goals (Barkley, 1997; Barnett et al., 2001; Carter, Krener, Chaderjian, Nortycutt, \& Wolfe, 1995; Knapp, Rohde, Lyszkowski, \& Johannpeter, 2002; MacPherson, Phillips, \& Sala, 2002; Silberstein et al., 1998).

The prevalence of ADHD is near 3\% to $8 \%$ of the school population (Andrade \& Scheuer, 2004; Bush et al., 1999;
Freire \& Pondé, 2005; Mattos, Saboya, Kaefer, Knijnik, \& Soncini, 2003; Szobot, Eizirik, Cunha, Langleben, \& Rohde, 2001). Given this elevated prevalence, it is fundamental to precisely identify the children who exhibit the disorder, based on the understanding of the related difficulties, so as to promote effective intervention. Given that, according to the reviewed literature, the executive functions have been shown to be compromised in individuals with ADHD (Barkley, 1997), it is increasingly important to develop and validate tests of executive functions, verifying whether such instruments discriminate between individuals with or without the disorder.

To develop evaluation instruments for executive functions, it is necessary to first understand what the components of these functions are. Some authors (e.g., Gazzaniga et al., 2002; Lezak, 1995) have proposed that a specific group of abilities is involved in the executive functions, including aspects of working memory, planning, flexibility, selective attentions and inhibitive control. Within such components, the present article focuses especially on selective attention, which corresponds to one of the functions of the attention system, and presupposes, concomitantly, orientation and concentration directed towards a stimulus, ignoring or decreasing the emphasis on other concurrent stimuli (Sternberg, 1996). According to Rosin (2001), this system allows response to a relevant target stimulus and suppression of irrelevant, distracting stimuli, as the response time to a target is usually greater when the target appears accompanied by distractions than when not accompanied by them.

Various instruments have been used to analyze attention processes, such as the Gottschaldt Shuffled Figures Test, the Odd Man Out Test, and Stroop's word-color procedure, which has been related more specifically to selective attention (Gazzaniga et al., 2002; Gil, 1999; Sternberg, 1996). The original version of the Stroop Test (Stroop, 1935) consisted of four parts. In the first part, the subjects had to read the names of colors written in black ink. In the second part, they read the names of colors written in colored ink, with no correlation between the name written and the color of the ink. In the third part, they had to say the name of the color of squares. Finally, in the fourth part, the same stimuli were presented as in the second part, but the subjects had to say the color of the ink with which the words had been written, disregarding the actual words.

The Victoria version (Regard, 1981/1999) has three steps. In the first, written words are presented (names of colors) written in black ink; in the second stage, colored circles (red, blue, yellow, green); and, in the last step, written words (names of colors) printed in colored ink, without any correlation between the color of the ink and the written word. In the first step, the subject must read the words as quickly as possible. In the second and third steps, the subject must say the color of the circles and printed words, respectively. 
Sensitivity to interference becomes clear in the last step of the test, as this task demands the selection of relevant information (in this case, attention to the color of the ink and suppression of the verbal content). In the general population, reaction time (RT) in this part of the task tends to increase in relation to the preceding steps, reflecting the so-called color-word interference effect. Patients with lesions on the frontal lobe require even more RT in the third step and can exhibit decreased performance, with more errors (Gil, 1999).

The study of Bush et al. (1999) analyzed performance in the Stroop task under functional magnetic resonance in adults with and without ADHD. The results revealed that both groups exhibited an interference effect in the task. However, patients with ADHD showed greater activation of the frontal-striate circuits, indicating hyperactivity in the anterior cingulate cortex, in contrast to normal adults. In fact, in a revision, Bush, Luu, and Posner (2000) point that various studies corroborate the idea that the anterior cingulate cortex is part of the network involved in attention, being important as much for cognitive regulation processes as for emotional ones.

According to Bush et al. (2000), the anterior cingulate cortex does not have a unitary structure or function; it is one of the principal divisions and, in cognitive aspects, it is related to the dorsal region, and, in affective aspects, to the rostroventral region. Thus, the dorsal region tends to be active in cognitive tasks, such as the Stroop color-word Test, and inhibited in emotional tasks, such as the Stroop emotional Test, whereas the opposite pattern tends to occur with the rostro-ventral region. Such a division is important, as alterations in each of these regions can cause specific attention problems or problems related either to neutral information or to emotional information. This may explain possible discrepancies observed in daily situations and formal tests, as formal tests usually employ neutral stimuli, whereas daily situations can require attention to information with an emotional content.

Sergeant, Geurts, and Oosterlaan (2002) conducted a review of research related to evaluations of executive functions in ADHD, among other pathologies. Among the studies, the majority employed children and adolescents with ADHD as subjects. A large part of these studies identified significant differences between groups with and without ADHD in the Stroop Test, although some did not reveal significant effects, or even revealed superior performance for the group with the disorder. Such discrepancies may be due to different measures used in the studies, because the score, total locution time, and/or RT in each item were all used.

In fact, studies with the Stroop Test have shown that, most of the time, the evaluation in terms of scores does not statistically discriminate between groups with and without ADHD (Scheres et al., 2004). The same thing was observed, for example, in the research of Willcutt et al. (2000), in which children with ADHD, from 8 to 16 years old, exhibited slightly lower scores in the Stroop Test in comparison with children without the disorder, and slightly higher scores when contrasted with a group with a reading disorder. The group formed of children with ADHD and reading disorder exhibited even lower performance. However, such differences were not statistically significant. Such findings reinforce the need to evaluate other measurements, such as RT, in studies with the Stroop Test.

In this context, RT, or the interval between the perception of a stimulus and the emission of a response, can be used as a performance measure. This is because it allows investigation of subtle deficits in the evaluated cognitive process, even when the subject commits no errors by omission or errors in action (submission of a response when a distraction arises or in the absence of any stimulus). In fact, this measurement of processing speed, especially in attention tasks, tends to be elevated in children with ADHD in comparison to control groups (Araújo, 2004).

In the face of the lack of attention evaluation instruments for children in Brazil, and additional evidence of selective attention in ADHD, the present study investigated the existence of possible differences between children with and without ADHD in terms of score and RT in a computerized version of the Stroop Test.

\section{Method}

\section{Participants}

Sixty-two children participated, between 8 and 12 years old, divided into two groups. Group 1 consisted of 31 children diagnosed with Attention Deficit Hyperactivity disorder (ADHD). Of these, 28 were boys and 3 girls, the average age being 124.4 months. In terms of the type of school attended, 18 were students from public schools, and 13 came from private institutions, namely, from two services of infantile psychiatry in the State of Sao Paulo. The selection of this group was done conforming to the nonprobabilistic intentional method (Bisquerra, Sarriera, \& Martínez, 2004), according to previously established inclusion and exclusion criteria.

The diagnosis of ADHD was done psychiatrically, by means of semi-structured interviews with one of the parents or legal guardians and teachers. A questionnaire of symptoms proposed by the DSM-IV-TR (APA, 2000) was used in the anamnesis with the parents, made up of 18 items corresponding to the nine items for inattentiveness and nine for hyperactivity/impulsivity, in addition to the criteria related to the presence of these symptoms before 7 years of age, in a minimum of two distinct contexts, with significant social, academic, or occupational behavior. In addition, two versions of the Abbreviated Conners Questionnaire (Goyette, Conners, \& Ulrich, 1978) were used, for parents and teachers, translated and adapted by Barbosa and Gouveia (1993) for Brazilian children. This questionnaire, which determines the quantity of the child's hyperactive behavior, consists of 42 and 40 items, respectively, to which the child's 
parents and teachers respond on a 4-point Likert-type rating scale, ranging from 0 (never) to 3 (always). Thus, all of the children diagnosed with ADHD met the DSM-IV-TR (APA, 2000) criteria, as well as obtaining scores above the minimum in the Abbreviated Conners Questionnaire.

For inclusion in Group 1, in addition to the psychiatric diagnosis, three inclusion criteria were employed. The first specified that the children must be attending a regular school. The second specified that their chronological age must be between 8 complete years and 11.5 years. The third specified that they could not be using any medication that could interfere with their cognitive or emotional behavior. After consulting neuropediatricians, it was decided that children using medication with methylphenidate should interrupt the medication for a minimum period of two days before undergoing the neuropsychological evaluation.

Four exclusion criteria were used; if any of them were met, the child was excluded from the study. Any child with a concomitant psychiatric diagnosis was excluded, including any developmental disorder, mental retardation, mood and anxiety disorders. This criterion was determined according to the criteria of the DSM-IV-TR (APA, 2000), based on semi-structured interviews with parents and teachers. Children with delayed neuropsychomotor development, sensory, motor, or neurological deficits, as well as children with intellectual deficiencies were excluded. Finally, children who attended special classes were excluded. However, the type of school attended was not an exclusion criterion; therefore, both children attending private and public schools were selected.

Group 2 was made up of a selection of 31 children from a database provided by Cozza (2005). This database included the data of children in the $3^{\text {rd }}$ and $4^{\text {th }}$ grades, all in the public school system in the State of Sao Paulo. Of these children, only those with a percentage lower than 75 in the Attention and Hyperactivity Deficit Scale (Benczik, 2000) were chosen, that is, those who did not exhibit symptoms of inattentiveness or hyperactivity. Such children were paired in age and sex with those of Group 1, resulting in a group with 28 boys and 3 girls with an average age of 123.9 months of age. Group 2 was characterized as not having a known history of ADHD or abnormal neuropsychomotor development, or intellectual deficiency (percentage below 50 in the Progressive Matrices Test-Raven, 1938; cf. Angelini, Alves, Custódio, Duarte, \& Duarte, 1999) or other pathologies that could alter cognitive behavior. The remainder of inclusion and exclusion criteria was similar to those for the group with ADHD, so that the groups would be comparable.

\section{Instrument}

Computerized Stroop Test. This version, developed by Capovilla, Montiel, Macedo and Charin (2005), evaluates selective attention, or capacity to attend to specific characteristics of a stimulus, ignoring characteristics irrelevant to the task. It was based on the Victoria version (Regard, 1981) and consists of three parts.

The first part consists of computerized presentation of the names of four colors (yellow, blue, green, and red), written in capital letters, Times New Roman font, size 72, in black. Each word appears six times and remains visible on the screen for an undetermined period of time. The order is semi-random, so that the same word never appears two consecutive times throughout the test. The subject's task is to read each word as quickly as possible. This part of the test is intended to obtain a baseline to evaluate the reading ability and determine whether this ability is high enough so as not to hinder the interference effect. This is because the effect of color-word interference may be absent if the reading ability is lower than expected.

In the second part, 24 colored circles are presented, 6 circles for each of the four colors (blue, red, yellow, and green), distributed semi-randomly. Each circle remains on the screen for 0.040 seconds. This time limitation of the presentation was adopted because research has shown that rapid presentation, with presentation under $50 \mathrm{~ms}$, renders conscious access to the presented content difficult and amplifies the color-word interference effect (MacLeod \& Rutherford, 1992; Mogg, Kentish, \& Bradley, 1993). The task is similar to the first part, having to name the color of the circle, to provide a baseline for the analysis of RT in the third part.

In the third and last part, the circles are replaced by written words, corresponding to the four colors, however the words are printed in colors that do not correspond to the written word (for example, the word "green" written in blue letters). The subject must name the color in which the word is written, ignoring the meaning of the written word.

For the computerized version, IBV software, developed by Macedo, Capovilla, Diana, and Covre (1998), was used, that allows recording of the participant's voice at each stimulus, as well as their RT. The experimenter operates the software, selecting the buttons "Stop," "Next," or "Pause" that appear in the lower right corner of the computer screen. This adaptation allows auditory reexamination of the subject's actions, enabling later qualitative and qualitative analyses.

\section{Procedure}

The study was initially approved by the Ethics in Research Committee of the University of Sao Francisco and authorized by infantile research services. Once the children and their guardians gave consent, data collection began. The Stroop Test was administered individually, taking about 20 minutes, using a laptop computer.

At the beginning of the test, the participant is told that the instrument is made up of three parts, the first one consisting of the reading of words, the second and third ones consisting of naming the colors as quickly as possible. 
The software records participant's score, RT, and performance time. Measurements of color-word interference score and color-word interference RT were used in this study.

For scoring purposes, 0 point was assigned for no response or an error, and 1 point for each correct response. The mean score was the mathematical average of the points obtained in each part of the test (maximum $=1$ point, minimum $=0$ ). Thus, the test generates three scores (mean word reading, naming of colored circles, and naming of colors of printed words) and a fourth score, the mean colorword interference effect, which corresponds to the score in Part 3 minus the score in Part 2 (Regard, 1981/1999).

For the purpose of analyzing RT, four measurements were taken: (a) mean RT in word reading, (b) mean RT in naming of the colored circles, (c) mean RT in naming of the colors of the printed words, and (d) mean RT in colorword interference, which corresponds to the mean RT in Part 3 minus the mean RT in Part 2.

In this study, only the mean color-word interference score and the mean color-word interference RT were considered, as these reflect most appropriately the mean color-word interference effect, that is, the alteration in color-word interference performance (i.e., score or RT) due to the incongruence in Part 3 between the color and the printed word. Only the performance of participants who achieved a score of $80 \%$ or better in Part 1, reading, was considered, as this variable is of extreme relevance for performance of the task.

\section{Results}

In the performance analysis on the Stroop Test, 2 participants out of the 62 did not obtain the minimum necessary score on Part 1 to allow analysis of performance on the test. Therefore, the data from these two children, as well as the data from their respective pairs, were excluded from the analysis.
The precision of the Stroop Test to measure RT and interference score was calculated considering the raw data on all of the 72 items. For RT, a Cronbach's alpha of .68 was obtained and a Spearman-Brown coefficient of .83 , both being satisfactory. For the interference score, a Cronbach's alpha of .82 and a Spearman-Brown coefficient of .84 were obtained, both sufficiently satisfactory.

Two measurements of interference were used to compare groups with and without ADHD: mean score in Part 3 minus mean score in Part 2, and mean RT in Part 3 minus mean RT in Part 2. Initially, outliers, whose performance was beyond two standard deviations of the average of the group, were excluded, as well as their respective pairs. This was the case of 2 outliers with ADHD in interference RT, and 3 outliers (1 with ADHD and 2 without) in interference score. Therefore, all told, 4 participants were excluded from RT analysis and 6 from interference score analysis.

Table 1 summarizes the descriptive statistics obtained for RT and interference score (i.e., the average in Part 3 minus the average in Part 2) in each group. For RT, the greater the difference between the Part 3 and Part 2, the greater the interference effect on directing attention to the relevant stimulus. For the interference score, the more negative the score resulting from the difference between Part 3 and Part 2, the greater the interference effect, that is, the lower the capacity to respond correctly to a target stimulus (in this case, the color in which the word was printed) in the presence of a distracting stimulus (i.e., the written word that names a color). In the present study, a greater RT with interference was observed in the group with ADHD than in the group without the disorder, but a lower interference score with distraction was not found.

In order to determine whether ANCOVA was adequate, fulfillment of the normality criteria of the distributions was verified, finding that the interference RT distribution satisfied normality requirements $(p=.179$ and $p=.200$, for the group with and without ADHD, respectively), but that the

Table 1

Interferential and Descriptive Statistics for Interference RT (in Thousandths of a Second) and Descriptive Statistics for Interference Scores in the Stroop Test for Groups with and without ADHD

\begin{tabular}{|c|c|c|c|c|c|c|c|}
\hline \multirow{2}{*}{$\begin{array}{l}\text { Interference in } \\
\text { the Stroop Test }\end{array}$} & \multirow{2}{*}{ Groups } & \multirow{2}{*}{$M$} & \multirow{2}{*}{$S D$} & \multicolumn{2}{|c|}{ Confidence interval of $95 \%$} & \multirow{2}{*}{$F$} & \multirow{2}{*}{$p$} \\
\hline & & & & Lower limit & Upper limit & & \\
\hline \multirow{3}{*}{ Interference RT } & ADHD & 0.785 & 0.053 & .678 & .892 & \multirow{3}{*}{$(1,54)=8.50$} & \multirow{3}{*}{.005} \\
\hline & & & & & & & \\
\hline & Without ADHD & 0.537 & 0.053 & .430 & .644 & & \\
\hline \multirow{2}{*}{ Interference Scor } & ADHD & -0.042 & 0.026 & -.094 & .010 & & \\
\hline & Without ADHD & -0.067 & 0.026 & -.119 & -.015 & & \\
\hline
\end{tabular}

Note. For interference RT, higher values imply a greater interference effect. For the interference score, lower values (i.e., the more negative this value) imply a greater interference effect. 
interference score did not $(p=.200$ and $p=.005$ for the group with ADHD and without ADHD, respectively).

Therefore, a univariate ANCOVA was conducted, with interference RT as the dependent variable, the group (with and without ADHD) as factor, and age and type of school as covariates. Age was used as covariate because the group with ADHD was, on average, older than the group without ADHD (124.4 months compared to 123.6 months). The school type was used as covariate because, in Brazil, there is a significant difference in the quality of teaching between private and public schools, as performance in private schools is usually better. Thus, to avoid possible differences between the groups due to age or type of school, these two variables were controlled with ANCOVA. As the type of school variable was categorical, public and private levels were dummy coded as 0 and 1 , respectively. The Levene test revealed homogeneity of variances $(p=.135)$, showing that ANCOVA was suitable.

The ANCOVA revealed a significant effect for the type of group on interference RT, $F(1,54)=8.50, p=.005, \mathrm{n}^{2}$ $=0.145$. No significant effects were found for the covariates of age $(p=.937)$ or type of school $(p=.231)$.

\section{Discussion}

This study investigated the difference between groups of children with and without ADHD in terms of interference score and interference RT in the Stroop Test. As this computerized version has only recently been developed, precision analyses were initially carried for both measurements, which provided sufficiently satisfactory coefficients.

As the measurement of Stroop interference score did not meet normality criteria, inferential analyses were conducted on the RT data only. Upon comparing children with and without ADHD with ANCOVA, it was observed that the children with ADHD showed greater interference effect on $\mathrm{RT}$ in the emission of a response to the stimulus than the children without ADHD. This statistically significant difference provides concurrent evidence to validate the Computerized Stroop Test, even after having controlled the effects of age and type of school. The covariates of age and school type did not yield significant effects.

These results corroborate the interference effect on RT in the Stroop Test as a valid measurement to discriminate between groups with and without ADHD. That is, when orientation and selection of a relevant stimulus are required while ignoring other competing stimuli, children with ADHD display greater RT in the task. In the author's studies (Stroop, 1935), time measurement was already used to discriminate the interference effect, which was replicated in other studies (e.g., Gazzaniga et al., 2002, Rosin, 2001; Sergeant et al., 2002).

Computerized application of the Stroop Test provides a great advantage to the analysis of such time measurements, as it allows precise recording of RT in thousandths of a second, increasing its sensitivity. Furthermore, computerization improves standardization of the conditions for presenting the stimuli and collecting responses, allowing greater rigor in the control of the conditions of the evaluation, making the test a more trustworthy resource for neuropsychological evaluation.

The results of this study should be investigated in greater detail in future studies in order to increase comprehension of the results of children with ADHD in the computerized version of the Stroop Test. An aspect to be observed is that the groups were not paired based on intelligence, because the scores in the Raven Progressive Matrices Test (1938/1999) were only used as a cutting point for the exclusion criteria. Thus, it is important that future studies pair subjects also in intelligence.

Other factors should also be investigated in greater detail, because, according to the literature (Houghton et al., 1999; Sergeant et al., 2002), many external variables may interfere in the evaluation of results from ADHD, such as the use of medication (especially methylphenidate), type of school, age, sex, and comorbidity, among others. It is important to study, as well, the intrinsic characteristics of each version of the Stroop Test. In the current version, for example, presentation is computerized, so each stimulus is presented isolated on the screen, and the next stimulus is only presented after the participant has responded to the previous stimulus. This eliminates interference from the distraction of presenting various stimuli simultaneously, as occurs, for example, in the Regard (1981/1998) pencil-and-paper version. If, on the one hand, this eliminates interference from distraction, on the other hand, it restricts the possibility of erroneous responses, and increases RT.

In order to provide continuity to studies employing the computerized Stroop Test in the evaluation of selective attention, new studies are being conducted, seeking to derive normative data for Brazilian children, which will allow neuropsychologists to compare patients' performances. Possible effects of important variables, such as sex, type of school, and age on performance in the Stroop Test in children with psychiatric disorders may be studied more thoroughly in this extensive normalizing investigation, verifying whether the same patterns observed in this study emerge, such as absence of an effect of age or school type.

\section{References}

American Psychiatric Association. (2000). Diagnostic and statistical manual of mental disorders $4^{\text {th }}$ ed. text revision. Washington, D.C.: Author. (Translation: C. Dornelles, Porto Alegre, RS: Artmed, 2002.).

Andrade, E.R., \& Scheuer, C. (2004). Analysis of the efficacy of methylphenidate using the abbreviated Conners questionnaire in attention deficit hyperactivity disorder. Neuropsychiatric Archives, 62, 81-85. 
Araújo, C. (2004). Neuropsychiatric evaluation of attention. In L.E.L.R. Valle \& F.C. Capovilla (Eds.), Multidisciplinary themes in neuropsychology and learning (pp. 501-505). Ribeirão Preto, São Paulo: Tecmedd.

Barbosa, G.A., \& Gouveia, V.V. (1993). The hyperactivity factor in the Conners Questionnaire: Conceptual validity and diagnostic standards. Themes, 46, 188-202.

Barkley, R.A. (1997). Behavioral inhibition, sustained attention, and executive functions: Constructing a unifying theory of ADHD. Psychological Bulletin, 121, 65-94.

Barnett, R., Maruff, P., Vance, A., Luk, E. S. L., Costin, J., Wood, C., \& Pantelis, C. (2001). Abnormal executive function in attention deficit hyperactivity disorder: The effect of stimulant medication and age on spatial working memory. Psychological Medicine, 31, 114-121.

Benczik, E.B.P. (2000). Manual of the Scale for the Attention Deficit Hyperactivity Disorder: Teachers'version. São Paulo: House of Psychology Editor.

Bisquerra, R., Sarriera, J.C., \& Matínez, F. (2004). Introduction to statistics: Computerized focus on the statistical package SPSS. Porto Alegre, RS: Artmed.

Bush, G., Frazier, J.A., Rauch, S.L., Seidman, L.J., Whalen, P.J., Jenike, M.A., Rosen, B.R., \& Biederman, J. (1999). Anterior cingulate cortex dysfunction in attention-deficit/hyperactivity disorder revealed by MRI and the Counting Stroop. Biological Psychiatry, 45, 1542-1552.

Bush G., Luu P., \& Posner M. (2000). Cognitive and emotional influences in anterior cingulate cortex. Trends in Cognitive Sciences, 4, 215-222.

Capovilla, A.G.S., Montiel, J.M., Macedo, E.C., \& Charin, S. (2005). Computerized Stroop Test. Itatiba, São Paulo: University São Francisco.

Carter, C. S., Krener, P., Chaderjian, M., Nortycutt, C., \& Wolfe, V. (1995). Asymmetrical visual-spatial attentional performance in ADHD: Evidence for a right hemispheric deficit. Biological Psychiatry, 37, 789-797.

Cozza, H.F.P (2005). Evaluation of executive function in children and correlation with attention and hyperactivity. Doctoral dissertation. University São Francisco, Itatiba, São Paulo.

Damásio, A.R. (1995). El error de Descartes [Descartes' error]. Barcelona: Grijalbo Mondadori. (Translation: D. Vicente \& G. Segurado, São Paulo: Companhia das Letras, 1996.).

Freire, A.C.C., \& Pondé, M.P. (2005). Pilot study of prevalence in attention deficit hyperactivity disorder among school children in the city of Salvador. Neuro-Psychiatric Archives, 63, 474478.

Gazzaniga, M.S., Ivry, R.B., \& Mangun, G.R. (2002). Cognitive neuroscience: The biology of the mind. New York: Norton.

Gil, R. (1999). Neuropsicología [Neuropsychology]. Barcelona: Masson. (Translation: M.A.A.S. Doria. São Paulo: Editora Santos, 2002).

Goldberg, E. (2001). The executive brain: Frontal lobes and the civilized mind. Oxford, UK: Oxford University Press. (Translation: R. Fiker \& M.E. Fiker, Rio de Janeiro: Imago Editor, 2002)
Goyette C.H., Conners C.K., \& Ulrich R.F. (1978). Normative data in revised Conners Parent and Teacher Rating Scales. Journal of Abnormal Child Psychology, 6, 221-36.

Houghton, S., Douglas, G., West, J., Whithing, K., Wall, M., Langsford, S., Powell, L., \& Carroll, A. (1999). Differential patterns of executive function in children with attention deficit hyperactivity disorder according to gender and subtype. Journal of Child Neurology, 14, 801-805.

Kerns, J. G., \& Berenbaum, H. (2003). The relationship between formal thought disorder and executive functioning component processes. Journal of Abnormal Psychology, 112, 339-352.

Knapp, P., Rohde, L.A., Lyszkowski, L., \& Johannpeter, J. (2002). Cognitive therapy-behavior in attention deficit hyperactivity disorder: Therapeutic manual. Porto Alegre, RS: Artmed.

Lezak, M.D. (1995). Neuropsychological assessment ( $3^{\text {rd }}$ ed.). New York: Oxford University Press.

Luria, A.R. (1973). Fundamentals of neuropsychology. (Translation: J.A. Ricardo, São Paulo, Edusp, 1981).

Macedo, E.C., Capovilla, F.C., Diana, C., \& Covre, P. (1998). Development of computerized evaluation instruments for cognitive functions in the $W W W$ : The possible and the necessary. In F. Capovilla, M.J. Gonçalves, \& E.C. Macedo (Eds.), Technology in Cognitive (Re)habilitation (pp. 21-32). São Paulo: Sociedade Brasileira de Neuropsicologia e Edunisc.

MacLeod, C., \& Rutherford, E.M. (1992). Anxiety and the selective processing of emotional information: Mediating roles of awareness, trait and state variables, and personal relevance of stimulus materials. Behavior Research and Therapy, 30, 479486.

MacPherson, S.E., Phillips, L.H., \& Sala, S.D. (2002). Age, executive function, and social decision making: Dorsolateral prefrontal theory of cognitive aging. Psychology and Aging, 17, 598-609.

Mattos, P. (2002). Neurological evaluation of ADHD. In E.C. Macedo, M.J. Gonçalves, F.C. Capovilla, \& A.L. Sennyey (Eds.), Technology in cognitive (re)habilitation (pp. 321-328). São Paulo: Edunisc.

Mattos, P., Saboya, E., Kaefer, H., Knijnik, M.P., \& Soncini, N. (2003). Neuropsychology of ADHD. In L.A. Rohde \& P. Mattos (Eds.), Principles and practices in ADHD (pp. 63-74). Porto Alegre, RS: Artmed.

Mogg, K., Kentish, J., \& Bradley, B.P. (1993). Effects of anxiety and awareness on color identification latencies for emotional words. Behavior Research and Therapy, 31, 559-567.

Raven, J. C. (1938). Progressive matrices. A perceptual test of intelligence. London: Lewis. (Translation: A.L. Angelini, I.C.B. Alves, E.M. Custódio, W.F. Duarte, \& J.L.M. Duarte. Matrizes Progressivas Coloridas de Raven: Escala Especial. Manual. São Paulo: CETEPP, 1999).

Raven, J, Raven, J. C. \& Court, J. H. (1998). Raven Manual. General Overview.Oxford: Oxford Psychologists Press. (Translation: A.L. Angelini, I.C.B. Alves, E.M. Custódio, W.F. Duarte, \& J.L.M. Duarte. Matrizes Progressivas Coloridas de Raven: Escala Especial. Manual. São Paulo: CETEPP, 1999). 
Regard, M. (1998). Cognitive rigidity and flexibility: A neuropsychological study. In O. Spreen \& E. Strauss (Eds.), A compendium of neuropsychological tests. Oxford, MA: Oxford University Press.

Rosin, F.M. (2001). Some experimental contributions in the study of the negative priming effect in selective attention tasks. Doctorate Examination. University of São Paulo, Ribeirão Preto, São Paulo.

Scheres, A., Oosterlaan, J., Geurts, H., Morein-Zamir, S., Meiran, N., Achut, H., Vlasveld, L., \& Sergeant, J.A. (2004). Executive functioning in boys with ADHD: Primarily an inhibition deficit? Archives of Clinical Neuropsychology, 19, 569-594.

Sergeant, J.A., Geurts, H., \& Oosterlaan, J. (2002). How specific is a deficit of executive functioning for attentiondeficit/hyperactivity disorder? Behavioral Brain Research, 130, 3-28.

Silberstein, R. B., Farrow, M., Levy, F., Pipingas, A., Hay, D. A., \& Jarman, F. C. (1998). Functional brain electrical activity mapping in boys with attention-deficit/hyperactivity disorder. Archives General Psychiatry, 55, 1105-1112.
Sternberg, R.J. (1996). Cognitive psychology. (Translation: M.R.B. Osório, Porto Alegre, RS: Medical Arts, 2000).

Stroop, J.R. (1935). Studies of interference in serial verbal reaction. Journal of Experimental Psychology, 18, 643-662.

Szobot, C., Eizirik, M., Cunha, R.D., Langleben, D., \& Rohde, L.A. (2001). Neuroimage in attention deficit hyperactivity disorder. Brazilian Review of Psychology, 23, 32-35.

Willcutt, E.G., Pennington B.F., Boada, R., Ogline, J.S., Tunick, K.R.A., Chhabildas, N.A., \& Olson, R.K. (2001). A comparison of the deficits in reading disability and attentiondeficit/hyperactivity disorder. Journal of Abnormal Psychology, 110, 157-172.

World Health Organization. (1992). The ICD-10 classification of mental and behavioral disorders: Clinical descriptions and diagnostic and guidelines. Geneva, Switzerland: Author. (Translation, Porto Alegre, RS: Medical Arts, 1993).

Received April 13, 2006 Revision received July 31, 2006 Accepted January 17, 2007 